\title{
PENGEMBANGAN MODEL BISNIS DAN STRATEGI PELAYANAN KESEHATAN XYZ
}

\section{BUSINESS MODEL DEVELOPMENT AND CARE SERVICE STRATEGY DEVELOPMENT OF XYZ}

\author{
Ardian Surya Nurhakim*), Ono Suparno*), dan Dodik Ridho Nurrochmat***) \\ ${ }^{*}$ PT. Telkom Indonesia \\ Jl. Raya Pajajaran, Bogor 16153 \\ **) Departemen Teknologi Industri Pertanian, Fakultas Teknologi Pertanian, Institut Pertanian Bogor \\ Gedung Fateta Lantai 2, Kampus IPB Dramaga, Bogor 16680 \\ ${ }^{* * *}$ Departemen Manajemen Hutan, Fakultas Kehutanan, Institut Pertanian Bogor \\ Jl. Ulin Kampus IPB Darmaga, PO BOX 168, Bogor 16680
}

\begin{abstract}
XYZ is a company engaged in the field of health care. Companies that grow and develop require the right business model in order to achieve their visions and missions. One business model that successfully changed the complex business concept to be simple and understandable is the Business Model Canvas (BMC) developed by Alexander Osterwalder and Yves Pigneur. The objectives of this research were to analyze business models of XYZ organization through business model canvas approach, to identify key factors as strengths and weaknesses affecting the operational of XYZ organization, to formulate a strategy design required for the development of XYZ organization. Out of the nine elements of BMC, four elements were selected as top priorities for the company to improve its business strategy i.e. the elements of key activities, customer relationships, customer segments, and revenue streams. The results of BMC also show that the management needs to improve its business model and strategy for future development of $X Y Z$ organization e.g. by adding outlets in strategic places, forming a marketing team, as well as holding periodic training of human resources to optimize HR function.
\end{abstract}

Keywords: business model, health care, $H R, B M C$

\begin{abstract}
Abstrak: XYZ merupakan perusahaan yang bergerak di bidang pelayanan kesehatan. Perusahaan yang bertumbuh dan berkembang membutuhkan model bisnis yang tepat guna mencapai visi dan misi perusahaan. Salah satu model bisnis yang berhasil mengubah konsep bisnis yang rumit menjadi sederhana dan mudah dipahami adalah Business Model Canvas (BMC) yang dikembangkan oleh Alexander Osterwalder dan Yves Pigneur. Tujuan dari penelitian ini adalah menganalisa model bisnis organisasi XYZ melalui pendekatan model bisnis kanvas, mengidentifikasi faktor-faktor kunci yang menjadi kekuatan serta kelemahan yang berpengaruh dalam operasional organisasi XYZ, merumuskan rancangan strategi yang diperlukan untuk pengembangan organisasi XYZ. Hasil dari sembilan elemen BMC dipilih empat elemen yang menjadi prioritas utama perusahaan XYZ untuk memperbaiki strategi bisnisnya yaitu pada elemen key activities, customer relationships, customer segments, dan revenue streams. Hasil BMC juga menunjukan bahwa perusahaan perlu melakukan perbaikan model bisnis dan strategi guna pengembangan organisasi XYZ kedepannya, seperti menambah gerai outlet di tempat yang dianggap strategis, membentuk tim marketing, serta melakukan pelatihan SDM secara berkala untuk mengoptimalkan fungsi SDM.
\end{abstract}

Kata kunci: model bisnis, pelayanan kesehatan, SDM, BMC

\footnotetext{
${ }^{1}$ Alamat Korespondensi:

Email: ardiansuryanurhakim@yahoo.com
} 


\section{PENDAHULUAN}

Dalam merealisasikan tingkat kesehatan yang optimal, diperlukan peran serta dari pemerintah, swasta, pribadi atau yayasan untuk memberikan dan menyelenggrakan berbagai upaya kesehatan yang salah satunya adalah dengan mendirikan berbagai sarana kesehatan, seperti rumah sakit, klinik pengobatan dan bersalin, praktek dokter dan bidan, apotek, laboratorium, gerai optik dan pusat kesehatan masyarakat (Puskesmas).

Banyaknya unit pelayanan kesehatan yang bermunculan seperti apotek, klinik, gerai optik, unit medical chekup akan menimbulkan persaingan. Salah satu prinsip dasar dalam memenangkan persaingan bisnis di unit pelayanan kesehatan adalah menerapkan model bisnis yang tepat untuk perusahaan; jika tidak bisa menerapkan model bisnis yang tepat, maka perusahaan akan kalah bersaing. Penerapan model bisnis yang tepat adalah cara suatu organisasi dapat bertahan. Untuk itu, setiap organisasi harus bisa manfaatkan sumber daya dan keberadaan unit pelayanan kesehatan secara maksimal.

Faktor yang sangat berpengaruh terhadap peningkatan kesehatan adalah faktor lingkungan dan perilaku, karena dipengaruhi oleh faktor lain, seperti lingkungan hidup pemukiman, pelestarian sumberdaya alam, pendidikan, agama, ekonomi, industri, penerangan, riset dan teknologi, dan perhubungan (Damairini, 2006).

Sebuah organisasi untuk mampu bersaing di dalam industri harus memiliki kompetensi agar memiliki daya saing. Organisasi dituntut untuk bekerja secara professional laiknya organisasi swasta (Keumala dan Unik, 2008). Sebuah organisasi dituntut memiliki misi yang jelas (Drucker, 1993), serta mampu bertahan dengan perubahan lingkungannya (Armitage, 1992). Seperti bisnis usaha lain, tujuan mendirikan perusahaan adalah untuk meningkatkan penjualan, mendapatkan laba, dan berkembang untuk berusaha menaikkan kinerjanya. Laba perusahaan bergantung pada besarnya penjualan, dan besarnya penjualan bergantung pada faktor-faktor kunci dalam menjalankan strategi atau model bisnisnya (Primandari, 2012).

XYZ merupakan perusahaan yang bergerak di bidang pelayanan kesehatan. Perusahaan yang tumbuh dan berkembang membutuhkan model bisnis yang tepat guna mencapai visi dan misi perusahaan. Untuk mencapai visi perusahaan yaitu menjadi perusahaan yang unggul dalam penyelenggaraan layanan kesehatan di Indonesia maka perusahaan perlu menyediakan layanan kesehatan yang berkualitas tinggi dengan harga yang kompetitif dan menjadi model pengelolaan korporasi kesehatan terbaik di Indonesia.

Berdasarkan latar belakang, perumusan masalah yang terjadi dalam menjalankan strategi bisnis adalah bagaimana mencari model bisnis yang sesuai di unit pelayanan kesehatan XYZ saat ini. Salah satu model bisnis yang berhasil mengubah konsep bisnis yang rumit menjadi sederhana dan mudah dipahami adalah business model canvas (BMC). Christensen (2001) mendifinisikan model bisnis sebagai sumber segala keunggulan kompetitif yang dimiliki oleh sebuah organisasi yang membedakannya dengan produk atau jasa perushaan lain.

Terdapat beberapa kajian yang menjadi tolak ukur dalam penelitian ini, pertama penelitian yang dilakukan oleh Amit dan Zott (2010) dengan judul Creating Value Throught Business Model Innovation. Kesimpulan dari penelitian yang dilakukan menyatakan bahwa seorang pimpinan perusahaan untuk melakukan perubahan model bisnis harus memperhatikan beberapa hal penting, yaitu kebaruan dari program yang dilaksanakan, komplementaritas dan efisiensi merupakan pemicu proporsi nilai bisnis model. Amit dan Zott (2012) juga melakukan penelitian dengan pendekatan BMC dalam menciptakan inovasi. Inovasi model bisnis dilakuan dengan menambahkan kegiatan baru, menghubungkan kegiatan dengan cara baru atau mengubah bagian tertentu untuk melakukan suatu kegiatan. Kedua, Aspara et al. (2011) melakukan penelitian tentang strategi degan judul Strategic management of business model transformation: lessons from Nokia. Penelitian tersebut bertujuan menawarkan konsep tentang bagaimana dan mengapa tingkat perubahan strategis perusahaan dapat membangun perbedaan historis di tingkat unit bisnis. Metode yang digunakan adalah studi historis kasus transformasi model bisnis korporasi Nokia yang berubah secara drastis yang terjadi antara tahun 1987 hingga tahun 1995. Hasil dari peneliltian tersebut menunjukkan bahwa kerja konseptual dan historis memengaruhi proses perubahan model bisnis serta menunjukkan bagaimana unit bisnis utama memberikan alternatif strategi dan kemampuan untuk proses transformasi tingkat korporasi. 
Berbagai penelitian telah dilakukan dalam hal penggunaan model bisnis dalam merumuskan strategi, baik di dalam maupun luar negeri. BMC merupakan pengembangan dari penelitian Alexander Osterwalder (2004) yang berjudul The Business Model Ontology a Proposition in a Design Science Approach. Penelitian tersebut menggunakan pendekatan studi kasus pada beberapa perusahaan ternama dan salah satu event organizer di Eropa. Tujuan dari penelitian tersebut adalah menentukan BMC yang akan dijalankan di masa mendatang dengan terlebih dahulu mengidentifikasi bentuk BMC yang telah dijalankan. Hasil dari penelitian tersebut menyatakan bahwa sebagian besar perusahaan raksasa melakukan pendekatan trial and error untuk memperkenalkan aspek yang baru dalam tujuan perbaikan model bisnis kanvas mereka.

Van der Heidjen (2010) meneliti tentang The Review of a Business Model Canvas, Research on Changing the Business Model for a Dutch Tour Operator. Permasalahan yang diangkat dari penelitian tersebut adalah operator tur dalam mencari pelanggan. Dengan ditunjang dengan perkembangan internet dan lesunya perekonomian Eropa maka operator travel di Belanda memutuskan untuk mengubah model bisnis mereka. Banyak dari operator tersebut menggunakan sarana internet untuk menggantikan gedung-gedung besar sebagai kantor mereka. Selain itu, adanya metode penjualan yang berbeda. Penelitian tersebut menggunakan beberapa sampel dari operator tur yang ternama di Belanda dan mewawancarai beberapa ahli bisnis untuk memberikan analisis di masa depan mengenai industri travel di Belanda.

Geisen et al. (2010) melakukan penelitian When and How to Innovate Your Business Model. Penelitian ini menggunakan metode studi kasus pada perusahaan baju fashion terbesar di dunia. Hasil penelitian tersebut menunjukkan bahwa dalam lingkungan bisnis yang semakin kompleks dan cepat berubah, organisasi harus memikirkan kembali model bisnis mereka. Organisasi perlu merubah dan meningkatkan model mereka, terutama selama periode gejolak ekonomi dan meningkatkan transformasi industri. Organisasi harus memastikan model bisnis yang sesuai dengan nilai pelanggan. Zhu et al. (2004) melakukan penelitian Model-driven Business Process Integration and Management: A Case Study With Bank Sino Pac Regional Service Platform. Dalam penelitian tersebut menggunakan alat analisis yang disebut Model Blue yang terdiri dari tiga bagian, yaitu design tools, managing tools, dan runtime enviroment. Hasil dari penelitian tersebut menunjukkan bahwa Model Blue membantu dalam mengembangkan metodologi/cara berbisnis yang telah dijalankan sehingga berdampak pada penigkatan kepuasan pelanggan.

Zook dan Allan (2011) mengkaji mengenai The Great Repeatable Business Model. Zook mengkaji terkait dengan diferensiasi adalah inti dari strategi berbagai sumber keunggulan kompetitif. Anda mendapatkan uang tidak hanya dengan melakukan dengan melakukan tugas yang berharga tetapi dengan dengan menjadi berbeda dengan pesaing dengan cara memungkinkan anda melayani pelanggan inti anda dengan lebih baik dan lebih menguntungkan. Cara terbaik untuk tumbuh biasanya dengan mereplikasi strategi terkuat. Perusahaan biasanya berkembang biasanya berkembang dalam satu atau lebih dari empat cara, yaitu mereka membuat atau membeli produk dan layanan baru, membuat atau memasuki segmen pelanggan baru, memasuki lokasi geografis yang baru atau memasuki jalur yang terkait dengan bisnis. Perusahaan dapat mengejar masing-masing strategi dalam berbagai cara, misalnya menambahkan harga baru atau jasa yang akan menarik bagi pelanggan baru. Kekuatan model berulan terletak pada cara sumber diferensiasi menjadi rutinitas perilaku dan sistem aktifitas yang semua orang di organisasi dapat memahami dan mengikuti sehingga ketika sebuah perusahaan menetapkan pertumbuhan tertentu ia mengetahui bagaimana mempertahankan diferensiasi yang menyebabkan keberhasilan.

Hone et al. (2011) mengkaji mengenai A Grounded Theory Study on the Business Model Structure of Google. Bisnis adalah suatu sistem, ketika bisnis dianggap sebagai suatu sistem, model bisnis bisa menjadi konfigurasi sistem penerbitan dan desain ulang. Model bisnis adalah kreasi dari pengusaha atau para sarjana dari sekolah bisnis. Cara cepat merancang model bisnis baru telah menjadi masalah yang penting. Jika akademisi dapat mengusulkan metodologi tentang prinsip desain model bisnis, maka praktisi atau pengusaha yang mampu menciptakan bisnis baru mereka tanpa membuang uang mereka secara percuma. Salah satu hal yang penting untuk mendesain model bisnis adalah bagaimana memahami struktur model bisnis perusahaan. Tujuan dari penelitian Hone Tsai ini adalah untuk mengusulkan metode sistematis baru yang mengidentifikasi struktur model bisnis perusahaan tertentu itu. Hone Tsai memilih Google sebagai kasus untuk menunjukan metode baru. Google 
telah menjalankan bisnis yang inovatif model yang sangat berbeda dengan model bisnistradisional dan dengan demikian Google adalah kasus yang layak untuk diteliti. Dengan mengekplorasi stuktur model bisnis yang dimiliki Google, diperoleh pemahaman bagaimana Google melakukan bisnis dari perspektif sistem bisnis. Setelah perusahaan memahami struktur model bisnis, perusahaan dapat merancang model bisnis untuk menghadapi tantangan masa depan.

Persaingan antar unit pelayanan kesehatan saat ini semakin ketat mengakibatkan pola persaingan yang terjadi menjurus ke win-lose situation karena tujuannya adalah killing for survival (Andriani, 2013). Dunia persaingan yang semakin ketat membuat sebuah organisasi harus memiliki visi, misi, dan ideide baru agar dapat beradaptasi terhadap perubahan lingkungan (Eppler et al. 2011). Perusahaan XYZ perlu mengetahui faktor-faktor kunci yang memengaruhi upaya pengelolaan XYZ unit bisnis Jakarta sebagai dasar dalam perumusan upaya-upaya strategis yang dapat dilakukan organisasi kedepannya. Perencanaan perbaikan hendaknya dilakukan di segala bidang organisasi agar perubahan yang dilakukan dapat meningkatkan performa perusahaan (Darmawati, 2007). Tujuan penelitian ini menganalisis model bisnis organisasi XYZ melalui pendekatan model bisnis kanvas. Penelitian ini dilakasanakan dalam ruang lingkup organisasi XYZ unit bisnis Jakarta. Fokus penelitian adalah menganalisa model bisnis XYZ saat ini dan faktor kunci apa saja yang memengaruhi strategi pengembangan XYZ.

Pembahasan penelitian dibatasi dalam lingkup kajian strategis, yaitu perumusan strategi pengembangan XYZ dengan menggunakan pendekatan BMC. Ruang lingkup penelitian mencakup gambaran model bisnis XYZ saat ini, faktor-faktor kunci yang memengaruhinya, perbaikan dari model bisnis, serta perumusan strategi alternatif sebagai pengembangan organisasi XYZ.

\section{METODE}

Penelitian ini dilaksanakan pada Organisasi XYZ unit bisnis Jakarta dengan lokasi kantor unit bisnis di Jl. Percetakan Negara dan Telemedika Farma 19 di jalan Pengadilan No. 4 Bogor. Penelitian dilaksanakan selama lima bulan, termasuk penyusunan proposal, studi literatur, dan pengambilan data di XYZ unit bisnis Jakarta dan di unit Telemedika Farma 19 Bogor, dimulai dari bulan Februari hingga Juni 2015. Pemilihan lokasi dilakukan dengan sengaja (purposive) mengingat obyek penelitian memiliki potensi untuk dikembangkan. Data yang digunakan dalam penelitian ini terdiri atas data primer dan data sekunder, baik yang diperoleh dari internal maupun eksternal organisasi. Data primer diperoleh melalui hasil observasi/pengamatan lapangan, kuesioner dan melakukan diskusi grup terfokus dengan jajaran pengelola XYZ, sedangkan data sekunder diperoleh dengan mengakses laporan kinerja organisasi XYZ dan melakukan studi pustaka. Teknik pengumpulan data dan informasi yang dilakukan dalam penelitian ini meliputi 1) observasi, yaitu melakukan pengamatan langsung di lapangan. 2) Metode wawancara, yaitu melakukan wawancara dengan metode Focus Grup Discussion (FGD) dengan manajemen pengelola XYZ Unit Bisnis Jakarta. 3) Kuesioner, yaitu dengan cara memberikan sejumlah pertanyaan tertulis kepada responden untuk mendapatkan informasi yang diinginkan.

Teknik pengolahan dan analisis data yang dilakukan meliputi 1) Analisis deskriptif kondisi XYZ saat ini. 2) Pemetaan model bisnis $X Y Z$ dengan menggunakan BMC, yaitu pemetaan model bisnis dengan melakukan 'potret' pada sembilan elemen BMC melalui diskusi grup terfokus dari responden. 3) Analisis SWOT masing-masing elemen, yaitu dilakukan analisis SWOT pada penelitian ini terhadap kesembilan elemen BMC. Dari hasil tersebut, diperoleh kekuatan dan kelemahan sebagai faktor strategis internal serta peluang dan ancaman sebagai faktor strategis eksternal melalui FGD. 4) Perbaikan strategi bisnis XYZ, yaitu hasil dari analisis SWOT digunakan peneliti untuk melakukan perbaikan terhadap model bisnis XYZ saat ini. 5) Perbaikan model bisnis XYZ, yaitu hasil rumusan dari hasil perubahan-perubahan yang terjadi pada model bisnis XYZ dan analsis SWOT yang telah disempurnakan. Hasilnya berupa satu atau beberapa strategi pengembangan XYZ.

Responden dalam penelitian ini merupakan responden internal XYZ. Responden merupakan badan pengelola atau badan pengurus XYZ. Responden merupakan orang yang mengetahui kondisi XYZ saat ini. Responden merupakan orang yang berperan atau ikut serta dalam perencanaan dan penetapan strategi pengembangan XYZ. Responden internal mengetahui dengan pasti faktor-faktor dari dalam dan luar organisasi yang 
memberi pengaruh terhadap organisasi. Faktor-faktor tersebut dinilai cukup oleh peneliti untuk mendesain BMC dan menyusun strategi pengembangan. Daftar responden untuk diskusi grup terfokus dapat dilihat pada Tabel 1 .

Tabel 1. Daftar responden

\begin{tabular}{lc}
\hline Jabatan & Jumlah (orang) \\
\hline Head of Regional Jakarta & 1 \\
Koordinator Telemedika Farma 8 & 1 \\
Koordinator Telemedika Farma 6 & 1 \\
Koordinator Telemedika Farma 7 & 1 \\
Koordinator Telemedika Farma 21 & 1 \\
\hline
\end{tabular}

Untuk mencapai tujuan yang diinginkan maka diperlukan program dan strategi bisnis yang sesuai dengan kondisi perusahaan saat ini. Langkah pertama dalam membuat strategi bisnis adalah melakukan identifikasi terhadap faktor-faktor kunci yang berpengaruh dalam organisasi XYZ dengan menggunakan pendekatan BMC. Proses selanjutnya adalah melakukan analisis SWOT yang dilakukan terhadap masing-masing elemen tersebut diatas. Identifikasi faktor-faktor kunci yang menjadi kekuatan dan kelemahan, serta peluang dan hambatan pada kesembilan elemen BMC memungkinkan peneliti mendapatkan hasil penilaian yang terfokus sehingga memperudah evaluasi kinerja organisasi saat ini. Hasil analisa SWOT tersebut kemudian menjadi dasar untuk membuat model bisnis perbaikan untuk kemudian dilakukan penyusunan strategi pengembangan organisasi XYZ untuk mencapai tujuan optimal.

\section{HASIL}

\section{Identifikasi Model Bisnis XYZ saat ini}

Tahap awal dalam menyusun strategi pengembangan XYZ adalah melihat struktur bisnis yang dimiliki XYZ saat ini melalui identifikasi kesembilan elemen BMC. Berdasarkan hasil wawancara dengan pihak internal XYZ diperoleh gambaran pengelolaan XYZ saat ini melalui pengelompokan hasil tersebut kedalam sembilan elemen BMC. Pengambilan data dilakukan dengan cara diskusi grup terfokus melalui responden internal XYZ yang berkaitan dengan sembilan elemen BMC XYZ saat ini (Gambar 1).

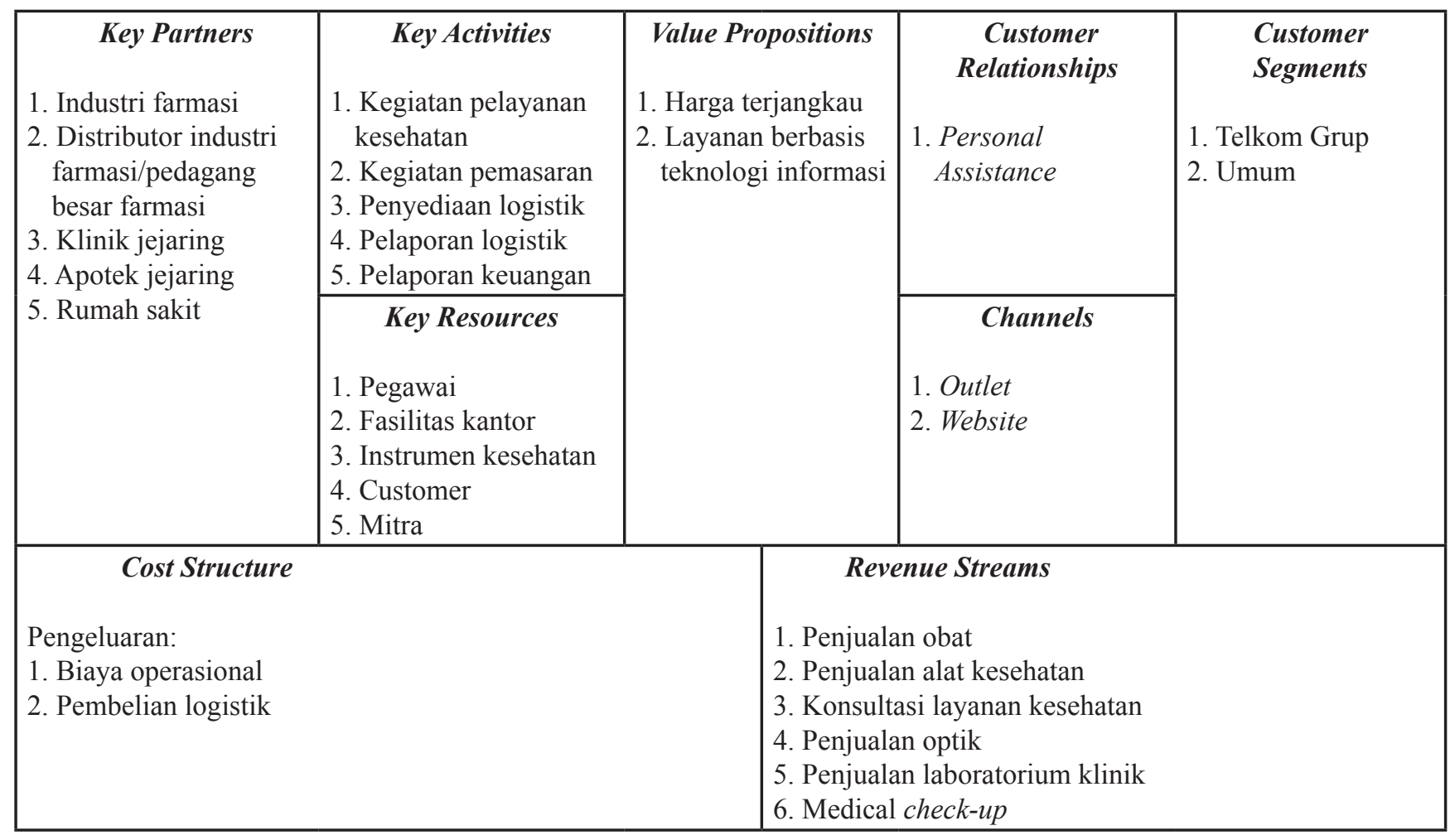

Gambar 1. Model bisnis kanvas saat ini 


\section{Identifikasi Bisnis Model Kanvas XYZ}

Penelitianinimelibatkan seluruhjajaran darimanajemen XYZ di regional Jakarta sebagai narasumber untuk memotret keadaan BMC saat ini. Pengambilan data dalam penelitian ini dilakukan dengan cara diskusi grup terfokus. Untuk peserta diskusi dipilih dari jajaran manajemen XYZ Regional Jakarta. Hal ini dilakukan karena para jajaran manajemen regional Jakarta merupakan pelaku yang paling berpengaruh terhadap pengambilan keputusan dalam perusahaan dan dianggap dianggap memiliki kompetensi yang lebih baik daripada staf.

Customer Segments menggambarkan sekelompok orang atau organisasi berbeda yang ingin dijangkau atau dilayani oleh perusahaan. Pelanggan XYZ masih di dominasi sebagian besarnya oleh pelanggan dari Telkom Group dan pelanggan dari perusahaan umum diluar Telkom Group masih sedikit. Hal ini dikarenakan XYZ baru melakukan ekspansinya pada bulan Desember Tahun 2013, sehingga masyarakat umum ataupun perusahaan lain belum terlalu mengenal XYZ. Value Proposition menggambarkan gabungan antara produk dan layanan yang menciptakan nilai spesifik untuk pelanggan. Berdasarkan obeservasi, dan Diskusi Grup Terfokus yang telah dilakukan maka value proposition yang ditawarkan $\mathrm{XYZ}$ adalah manfaat dari layanan kesehatan yang berkualitas dengan harga yang bersaing dan layanan yang memadai. Secara umum value proposition dari segi produk yang ditawarkan $\mathrm{XYZ}$ adalah harga yang terjangkau dan sistem pelayanan berbasis teknologi informasi.

Channels menggambarkan bagaimana sebuah perusahaan berkomunikasi dengan segmen pelanggannya dan menjangkau mereka. XYZ menggunakan channels distribusi langsung milik sendiri seperti klinik, apotek, dan gerai optik dan laboratorium milik sendiri. Dalam menjalankan komunikasi pemasaran, XYZ menggunakan media dalam bentuk spanduk, banner, dan poster. Media komunikasi modern yang digunakan oleh XYZ antara lain: website perusahaan, email, dan telepon.

Customer Relationship mendeskripsikan jenis hubungan yang dibangun perusahaan dengan segmen pasar tertentu. Sumber revenue perusahaan berasal dari customer-nya sehingga customer relationship menjadi faktor yang sangat penting dalam menjaga keberlangsungan perusahaan. Customer relationship yang telah dilakukan XYZ melalui pendekatan hubungan didasarkan pada interaksi manusia. Customer service dari XYZ menanyakan kepuasan terhadap produk dan layanan yang telah diperoleh dari XYZ.

Revenue stream adalah untuk menggambarkan arus pendapatan yang dihasilkan perusahaan dari masingmasing segmen pelanggan. Revenue stream XYZ didapat dari penjualan obat apotek, konsultasi layanan kesehatan, penjualan alat kesehatan, penjualan optik, penjualan pemerikasaan laboratorium, dan penjualan medical check up. Pendapatan lain XYZ juga diperoleh dari kerja sama antara $X Y Z$ dengan perusahaan mitra yang memberikan kepercayaan kepada XYZ untuk mengelola kesehatan para karyawanya.

Key Resources menggambarkan aset-aset terpenting yang dimiliki $\mathrm{XYZ}$ agar sebuah tujuan perusahaan dapat tercapai. Berdasarkan obeservasi, dan diskusi Grup Terfokus yang telah dilakukan XYZ memiliki key resources antara lain: 1) pegawai, 2) fasilitas kantor, 3) instrumenkesehatan, 4) customer, 5) mitra pengadaan logistik. Untuk menjalankan kegiatan bisnisnya, XYZ membutuhkan tenaga kerja yang bekerja sesuai perannya masing-masing di setiap divisi. Fasilitas kantor merupakan key resource yang memiliki peran untuk memudahkan para karyawan untuk melakukan aktivitasnya.

Key activities XYZ dapat di identifikasi antara lain: 1) kegiatan pelayanan kesehatan, 2) kegiatan pemasaran, 3) kegiatan pelayanan pemasaran, 4) penyediaan stok produk, 5) kegiatan pelaporan ketersediaan stok produk, 6) kegiatan penanganan transaksi pendapatan dan pengeluaran (laporan keuangan). Kegiatan utama yang dilakukan adalah memberikan pelayanan kesehatan yang menyeluruh kepada seluruh lapisan masyarakat indonesia melalui pengendalian utilisasi dan biaya tanpa meninggalkan mutu untuk memberikan pelayanan kesehatan yang efektif dan efisien, yang didukung dengan sistem Delivery Manage Care yang terintegrasi dengan provider kesehatan. Serta mengelola pelayanan kesehatan sesuai dengan kebutuhan, keinginan dan kemampuan corporate dalam segi pengendalian biaya.

Key Partnership XYZ memiliki beberapa mitra penunjang kegiatan bisnisnya yaitu PT. Telkom Indonesia Tbk, industri farmasi, pedagang besar farmasi dan rumah sakit. partner dalam sebuah bisnis sangat penting karena dapat mempermudah dan mempercepat proses bisnis yang ada (Tuten dan Urban, 2001). 
Untuk pengadaan logistik yang terstandarisasi maka XYZ berkeja sama dengan berbagai industri farmasi, baik industri farmasi penanaman modal asing (PMA) maupun penanaman modal dalam negeri (PMDN) dan untuk mendistribusikan logistik ke seluruh Indonesia, XYZ menggunakan beberapa mitra Pedagang Besar Farmasi (PBF).

Cost structure adalah komposisi biaya untuk mengoperasikan organisasi mewujudkan proposisi nilai yang diberikan kepada customer. Pengeluaran XYZ terdiri dari biaya operasional produk dan jasa. Sedangkan pendapatan XYZ berasal dari penjualan produk dan jasa dari perorangan, instansi pemerintah, instansi swasta, dan mitra dari XYZ. Pengeluaran XYZ terdiri dari biaya operasional produk dan jasa.
Pendapatan XYZ berasal dari penjualan produk dan jasa dari perorangan, instansi pemerintah, instansi swasta, dan mitra dari XYZ.

\section{Analisis SWOT Model Bisnis Kanvas XYZ}

Setelah mengidentidikasi elemen BMC perusahaan XYZ saat ini maka tahap selanjutnya adalah melakukan analisis SWOT pada setiap elemen BMC pada saat ini. Dalam melakukan analisis SWOT penulis berpedoman pada tahapan diskusi grup tefokus yang telah dijalankan (Tabel 2). Hasil dari analsisis SWOT ini dapat digunakan untuk menyempurnakan model bisnis yang telah diterapkan sehingga bisnis diharapkan akan semakin berkembang.

Tabel 2. Hasil analisis SWOT berdasarkan sembilan elemen BMC pada perusahaan XYZ

\begin{tabular}{|c|c|c|c|c|}
\hline Elemen & Kekuatan & Kelemahan & Peluang & Ancaman \\
\hline $\begin{array}{l}\text { Customer } \\
\text { Segments }\end{array}$ & $\begin{array}{l}\text { Mayoritas pelanggan } \\
\text { internal memberikan } \\
\text { pemasukan tetap }\end{array}$ & $\begin{array}{l}\text { Pelanggan eksternal } \\
\text { masih sedikit }\end{array}$ & Market masih luas & Banyak kompetitor \\
\hline $\begin{array}{l}\text { Value } \\
\text { Proposition }\end{array}$ & $\begin{array}{l}\text { Memiliki layanan } \\
\text { kesehatan yang } \\
\text { memadai guna } \\
\text { memenuhi kebutuhan } \\
\text { para customer seperti } \\
\text { klinik dokter, apotek, } \\
\text { laboratorium klinik, } \\
\text { dan optik. }\end{array}$ & $\begin{array}{l}\text { Sering terjadi perubahan } \\
\text { formularium obat }\end{array}$ & $\begin{array}{l}\text { berpeluang besar } \\
\text { mengembangkan pangsa } \\
\text { pasar di Indonesia. }\end{array}$ & $\begin{array}{l}\text { Bila tidak ada inovasi dari } \\
\text { strategi bisnis yang lama, } \\
\text { akan sulit dengan pesaing } \\
\text { dalam mengembangkan } \\
\text { pasar di Indonesia }\end{array}$ \\
\hline Channels & $\begin{array}{l}\text { Saluran distribusi yang } \\
\text { digunakan oleh XYZ } \\
\text { milik sendiri sehingga } \\
\text { dapat menekan biaya } \\
\text { operasional. }\end{array}$ & $\begin{array}{l}\text { Saluran distribusi XYZ } \\
\text { hanya di kota-kota besar } \\
\text { saja, belum menjangkau } \\
\text { kota-kota kecil }\end{array}$ & $\begin{array}{l}\text { XYZ masih punya } \\
\text { peluang bagus untuk } \\
\text { membuat saluran } \\
\text { distribusi produk dan } \\
\text { layanan untuk kota-kota } \\
\text { kecil se-Indonesia }\end{array}$ & $\begin{array}{l}\text { Bila tidak dapat } \\
\text { memaksimalkan sistem } \\
\text { informasi, maka XYZ } \\
\text { akan sulit menyampaikan } \\
\text { produk dan layananan } \\
\text { XYZ kepada customer } \\
\text { eksternal }\end{array}$ \\
\hline $\begin{array}{l}\text { Customer } \\
\text { Relationships }\end{array}$ & $\begin{array}{l}\text { XYZ memberikan } \\
\text { harga khusus untuk } \\
\text { produk dan layanan } \\
\text { bagi pelanggan } \\
\text { setianya. }\end{array}$ & $\begin{array}{l}\text { Masih belum maksimal } \\
\text { dalam menjalin } \\
\text { komunikasi kepada } \\
\text { pelanggannya }\end{array}$ & $\begin{array}{l}\text { XYZ memiliki sistem } \\
\text { informasi yang handal, } \\
\text { bila dimaksimalkan } \\
\text { akan berpeluang } \\
\text { mempertahankan } \\
\text { customer lama dan } \\
\text { menambah customer baru. }\end{array}$ & $\begin{array}{l}\text { Kurang maksimalnya } \\
\text { komunikasi yang dilakukan } \\
\text { XYZ terhadap keseluruhan } \\
\text { pelanggan XYZ terutama } \\
\text { pelanggan eksternal dapat } \\
\text { berpotensi pindahnya } \\
\text { pelanggan XYZ kepada } \\
\text { pesaing dan pelanggan } \\
\text { baru sulit dijangkau. }\end{array}$ \\
\hline $\begin{array}{l}\text { Revenue } \\
\text { Stream }\end{array}$ & $\begin{array}{l}\text { Arus pendapatan XYZ } \\
\text { saat ini bersumber } \\
\text { dari penjualan obat, } \\
\text { jasa konsultasi } \\
\text { kesehatan, penjualan } \\
\text { optik, medical chek } \\
\text { up dan pemeriksaan } \\
\text { laboratorium }\end{array}$ & $\begin{array}{l}\text { Arus pendapatan hanya } \\
\text { didapat dari peserta atau } \\
\text { pelanggan dari Telkom } \\
\text { grup }\end{array}$ & $\begin{array}{l}\text { Dengan layanan kesehatan } \\
\text { yang semakin prima, XYZ } \\
\text { berpeluang besar untuk } \\
\text { meningkatkan revenue } \\
\text { streams nya, terutama } \\
\text { revenue streams dari } \\
\text { pelanggan diluar Telkom } \\
\text { grup. }\end{array}$ & $\begin{array}{l}\text { Kurang mengenalnya } \\
\text { masyarakat umum tentang } \\
\text { XYZ adalah salah satu } \\
\text { faktor mengapa pendapatan } \\
\text { pelanggan dari luar Telkom } \\
\text { grup sangat kecil, bila } \\
\text { XYZ tidak bisa membuat } \\
\text { strategi yang sesuai maka } \\
\text { potensi untuk menjaring } \\
\text { pelanggan umum akan } \\
\text { sangat sulit. }\end{array}$ \\
\hline
\end{tabular}


Tabel 2. Hasil analisis SWOT berdasarkan sembilan elemen BMC pada perusahaan XYZ (Lanjutan)

\begin{tabular}{|c|c|c|c|c|}
\hline Element & Kekuatan & Kelemahan & Peluang & Ancaman \\
\hline Key Resources & $\begin{array}{l}\text { Layanan kesehatan } \\
\text { berbasis teknologi } \\
\text { informasi yang handal. }\end{array}$ & $\begin{array}{l}\text { Manajemen masih belum } \\
\text { bisa memaksimalkan } \\
\text { sumberdaya untuk } \\
\text { mendapatkan revenue } \\
\text { stream. }\end{array}$ & $\begin{array}{l}\text { Harga obat yang } \\
\text { kompetitif menjadi daya } \\
\text { tarik tersendiri bagi } \\
\text { pelanggan eksternal XYZ. }\end{array}$ & $\begin{array}{l}\text { Bila masalah personalia } \\
\text { tidak segera diatasi akan } \\
\text { menggangu operasional } \\
\text { XYZ, khususnya untuk } \\
\text { menjaring pelanggan } \\
\text { eksternal XYZ. }\end{array}$ \\
\hline Key Aktivities & $\begin{array}{l}\text { Kegiatan pelayanan } \\
\text { berbasis teknologi } \\
\text { informasi. }\end{array}$ & $\begin{array}{l}\text { Beberapa kendala terjadi } \\
\text { terhadap penyediaan stok } \\
\text { barang terutama produk } \\
\text { yang fast moving. }\end{array}$ & $\begin{array}{l}\text { Penawaran jasa } \\
\text { pengadaan produk dari } \\
\text { mitra yang semakin } \\
\text { banyak, menjadikan XYZ } \\
\text { memiliki beberapa pilihan } \\
\text { untuk menggunakannya }\end{array}$ & $\begin{array}{l}\text { Biaya operasional yang } \\
\text { tinggi dalam menjalankan } \\
\text { key activities XYZ dimasa } \\
\text { datang }\end{array}$ \\
\hline $\begin{array}{l}\text { Key } \\
\text { Partnership }\end{array}$ & $\begin{array}{l}\text { Memiliki mitra dari } \\
\text { berbagai perusahaan } \\
\text { Telkom grup sehingga } \\
\text { menunjang untuk } \\
\text { kegiatan operasional. }\end{array}$ & $\begin{array}{l}\text { XYZ belum memiliki } \\
\text { modal usaha yang kuat } \\
\text { untuk berkembang secara } \\
\text { ekstrim. }\end{array}$ & $\begin{array}{l}\text { Dengan adanya } \\
\text { kepercayaan dari mitra } \\
\text { selama bekerjasama } \\
\text { dengan XYZ, maka } \\
\text { akan berpotensi jalinan } \\
\text { kerjasama antara XYZ } \\
\text { dengan mitra berlangsung } \\
\text { secara kesinambungan. }\end{array}$ & $\begin{array}{l}\text { Klausul kerjasama } \\
\text { dengan mitra adalah } \\
\text { bersifat kontrak. Dan } \\
\text { memungkinkan kontrak } \\
\text { dengan mitra tidak } \\
\text { berlanjut, padahal } \\
\text { keberadaan mitra dirasa } \\
\text { sangat penting untuk } \\
\text { mendukung pencapaian } \\
\text { pengelolaan XYZ. }\end{array}$ \\
\hline Cost Structure & $\begin{array}{l}\text { XYZ berkerja sama } \\
\text { dengan berbagai mitra } \\
\text { dalam pengadaan } \\
\text { logistik sehingga } \\
\text { dapat menekan biaya } \\
\text { operasional. }\end{array}$ & $\begin{array}{l}\text { Belum dapat mengontrol } \\
\text { secara maksimal } \\
\text { mitra XYZ yang yang } \\
\text { menggunakan sistem } \\
\text { kapitasi, sehingga kondisi } \\
\text { dilapangan masih ada } \\
\text { mitra yang menggunakan } \\
\text { biaya operasional } \\
\text { melebihi biaya kapitasi } \\
\text { yang diberikan oleh XYZ }\end{array}$ & $\begin{array}{l}\text { Dengan reputasi XYZ } \\
\text { sebagai salah satu anak } \\
\text { perusahaan BUMN } \\
\text { terbesar di Indonesia } \\
\text { memungkinkan } \\
\text { menambah jalinan } \\
\text { kerjasama dengan } \\
\text { berbagai mitra baik mitra } \\
\text { internal maupun eksternal } \\
\text { sehingga mampu menekan } \\
\text { biaya operasional. }\end{array}$ & $\begin{array}{l}\text { Kecenderungan timbulnya } \\
\text { biaya operasional yang } \\
\text { semakin tinggi di masa } \\
\text { depan. }\end{array}$ \\
\hline
\end{tabular}

\section{Rekomendasi Pemilihan Strategi Bisnis bagi XYZ}

Beberapa inisiatif strategi atau program yang perlu dilakukan XYZ terkait perbaikan BMC yang ada saat ini antara lain:

a) Customer Segments (Strengths - Opportunities) Membentuk staf marketing khusus untuk menangani customer segments dari peserta diluar Telkom grup.

b) Value Propositions (Strengths - Opportunities)

Mengoptimalkan fungsi layanan dan fasilitas XYZ untuk para customers.

c) Channels (Weaknesses - Opportunities)

Melakukan promosi secara intensif terkait produk dan layanan XYZ kepada customer segments.

d) Customer Relationships (Weaknesses - Threats) Membentuk staf khusus customer care untuk mengawal kegiatan para customers.

e) Revenue Streams (Strengths - Opportunities) Menambah gerai outlet kesehatan XYZ di beberapa lokasi yang dianggap strategis. f) Key Resources (Weaknesses - Threatst)

Mengadakan pelatihan untuk seluruh staf

g) Key Activities (Weaknesses - Threats)

Menetapkan aktivitas kunci pada prioritas penjualan yang menghasilkan profit tertinggi.

h) Key Partners (Weaknesses - Opportunities)

Menambah dan mengotpimalkan jalinan kerjasama dengan berbagai mitra untuk menangani kebutuhan XYZ.

i) Cost Structure (Strengths - Treats)

Merancang ulang kegiatan perencanaan untuk pengeluaran biaya operasional. Model bisnis perbaikan XYZ bisa dilihat pada Gambar 2.

Hasil dari sembilan elemen BMC dipilih empat elemen yang menjadi prioritas utama perusahaan XYZ untuk memperbaiki strategi bisnisnya. Pada gambar 2 terlihat bahwa ada perubahan pada elemen key activities, customer relationships, customer segments, dan revenue streams yang dirasa oleh manajemen perlu dilakukan perubahan pada tiap elemen tersebut. Pada key activities 
perlu ditambahkan pelatihan SDM dikarenakan masih minim pelatihan untuk para karyawan, pada customer segments dilakukan kerjasama dengan BPJS dan Corporate dikarenakan BPJS dan Corporate dapat meningkatkan revenue, pada revenue streams dilakukan layanan hemodialisa karena layanan ini banyak dibutuhkan oleh pelanggan sementara ketersediaan layanan hemodialisa di Indonesia masih terbatas, pada customer relationships dilakukan layanan homecare untuk memudahkan pelanggan mendapat layanan kesehatan. Secara keseluruhan model bisnis XYZ sudah sesuai, hanya perlu dimaksimalkan kinerjanya pada masing-masing elemen tersebut.

\section{Implikasi Manajerial}

Beberapa inisiatif implikasi manajerial yang perlu dilakukan XYZ terkait perbaikan strategi meliputi: pengembangan ekspansi pasar dimulai dengan membuka outlet di tempat yang dianggap strategis; membentuk tim marketing untuk menjangkau pelanggan baru terutama pelanggan dari luar Telkom grup seperti menjaring peserta BPJS dari keluarga peserta XYZ ataupun kerabat dekat pelanggan Telkom grup; melakukan pelatihan SDM secara berkala, program ini bertujuan untuk mengoptimalkan fungsi SDM baik itu yang bersifat kompeteni maupun motivasi.

\section{KESIMPULAN DAN SARAN}

\section{Kesimpulan}

Model bisnis XYZ saat ini dirasa kurang maksimal, sehingga perlu dilakukan perbaikan di beberapa elemen, seperti di elemen key activities, customer segments, key resources, dan juga perlu dioptimalkan elemenelemen yang lainnya. Layanan yang berbasis teknologi informasi dan harga yang terjangkau merupakan faktor yang menjadi kekuatan XYZ saat ini, sedangkan belum dikenalnya XYZ oleh pelanggan diluar Telkom Grup serta outlet XYZ masih belum berada di tempat yang strategis merupakan kelemahan XYZ saat ini. Perbaikan model bisnis dan strategi diperlukan guna pengembangan organisasi XYZ kedepannya, seperti menambah gerai outlet di tempat yang dianggap strategis, membentuk tim marketing, serta melakukan pelatihan SDM secara berkala untuk mengoptmalkan fungsi SDM.

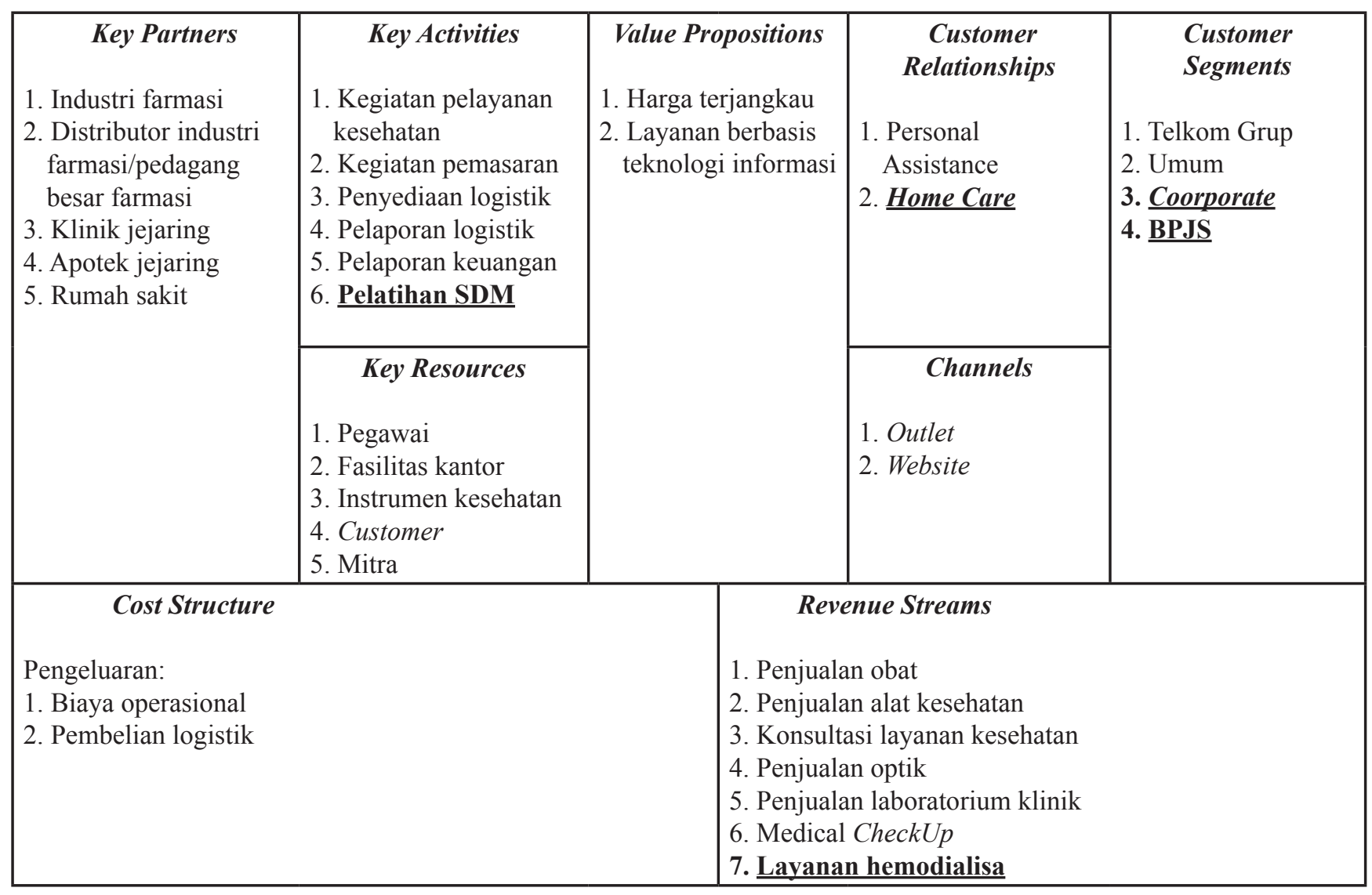

Gambar 1. Model bisnis kanvas perbaikan 


\section{Saran}

Saran untuk penelitian selanjutnya perlu dilakukan implementasi strategi sampai kepada evaluasi untuk memperkaya penelitian mengenai pengembangan strategi bisnis pada pelayanan kesehatan XYZ.

\section{DAFTAR PUSTAKA}

Amit R, Zott C. 2010. Creating value through business model innovation. IESE Business School Working Paper 870: 1-17.

Amit R, Zott C. 2012. Creating value through business model innovation. Journal MIT Sloan Management Review 53 (3):41-49.

Andriyani D. 2013. Pendekatan blue ocean strategy untuk meningkatkan strategi pelayanan obat di apotek K-24 Antapani. Jurnal Manajemen Bisnis 5 (2): $1-5$.

Armitage JL. 1992. Strategic Management For Public Accounting. The CPA.

Aspara J, Laukia A, Tikkanen H. 2011. Strategic management of business model transformation: lessons from Nokia. Journal of Management Decision 49(4):622-647. https://doi. org/10.1108/00251741111126521.

Christensen CM. 2001. The past and futureof competitive advantage. MIT Sloan Management Review 42(2): 105-109.

Damairini D. 2006. Analisis pelayanan kesehatan unit swadaya daerah. [tesis]. Bogor: Institut Pertanian Bogor.

Darmawati A. 2007. Mengelola suatu perubahan dalam organisasi. Jurnal Ilmu Manajemen 3(1).

Drucker PF. 1993. Managing The Non-Profit Organization, Practices \& Principles. London: Butterworth-Heinemann.

Eppler MJ, Hoffmann F, Bresciani S. 2011. New business models through collaborative idea generation. International Journal of Innovation
Management 15(6): 1323-1341. https://doi. org/10.1142/S1363919611003751.

Giesen, Edward, Riddleberger, Eric, Crhristner, Richard, Regna B. When and how to innovate your business model. Strategy \& Leadership 38(4): 17-26, https://doi.org/10.1108/10878571011059700

Hone T, De Lin, Hey Su. 2011. A grounded theory on the business model structure of google. International Journal of Electronic Business Management 9(3): 231-242

Keumala H, Unik A. 2008. Perencanaan strategik universitas lampung dalam perspektif balanced scorecard. Jurnal Bisnis dan Manajemen 4(3): 222-330.

Osterwalder A. 2004. The Business model ontology a preposition a design science approach. [Disertasi]. Zurich: Universite De Lausanne Ecole Des Hautes Estudes Commerciales.

Primandari K. 2012. Analisis strategi bersaing dalam bisnis apotek [tesis]. Yogyakarta: Universitas Gadjah Mada.

Tuten TL, Urban DJ. 2001. An expended model of business to business partnership formation and success. Journal of Industrial Marketing Management 30(2): 149-164. https://doi. org/10.1016/S0019-8501(00)00140-1.

Van der Heiden. 2010. The review of a business model canvas, research on changing the business model for a Dutch Tour Operator. Journal University of Twente 32(3): 96-99.

Zhu J, Tian Z, Li T, Sun W. 2004. Model-driven business process integration and management: A case study with the Bank SinoPac regional service platform. IBM Journal of Research and Development 48: 5-6. https://doi.org/10.1147/ rd.485.0649.

Zook C, Allan J. 2011. The repeatable business model: leveraging a simple formula allows corporations to createnew and more-lasting differentiation. Journal Harvard Business Review 7(1): 1-10. 